\title{
A delicate child
}

\section{Hugo von Habermann (1849-1929). Ein Sorgenkind, 1886. Nationalgalerie, Staatliche Museen zu Berlin. Oil on canvas, cm. 178 x 238. Inv.: A I 634. Photograph: Joerg P. Anders.}

The painting by Hugo von Habermann (Fig. 1) effectively depicts the nature of both disease and medicine.

The scene deals with a medical consultation made by a family doctor on a delicate child (as the canvas title suggests) before the eyes of the mother, who looks on with fear for the health of her daughter.

The careful auscultation that the physician is performing, icon of clinical activity in medicine, recalls the biological sphere with which disease occurs, through signs and symptoms which can be submitted to semiological investigation and measurement; those signs are the target of medicine as an applied science. The look of the mother instead suggests the human dimension of sickness, which does not end at the biological boundary, but rather trespasses onto the person to reach the family network and friendships.
The physician is totally involved in his clinical gesture, but the environment where he works recalls him also the human dimension of disease, which dominates the main feeling of the scene.

The preparatory sketches for this work bear witness to the careful research performed by the artist to achieve this picture. He used a noblewoman as a model for the mother - an uncommon fact - of whom von Habermann made a portrait, and therefore the need to dedicate particular attention to this face.

In this fin de siècle oleography the quiet realism of the details which compose the wisely scored scene introduces us to a human story. Here the professional act is the opportunity for a relationship and not the chance to impair the mystery of which the human adventure vibrates.

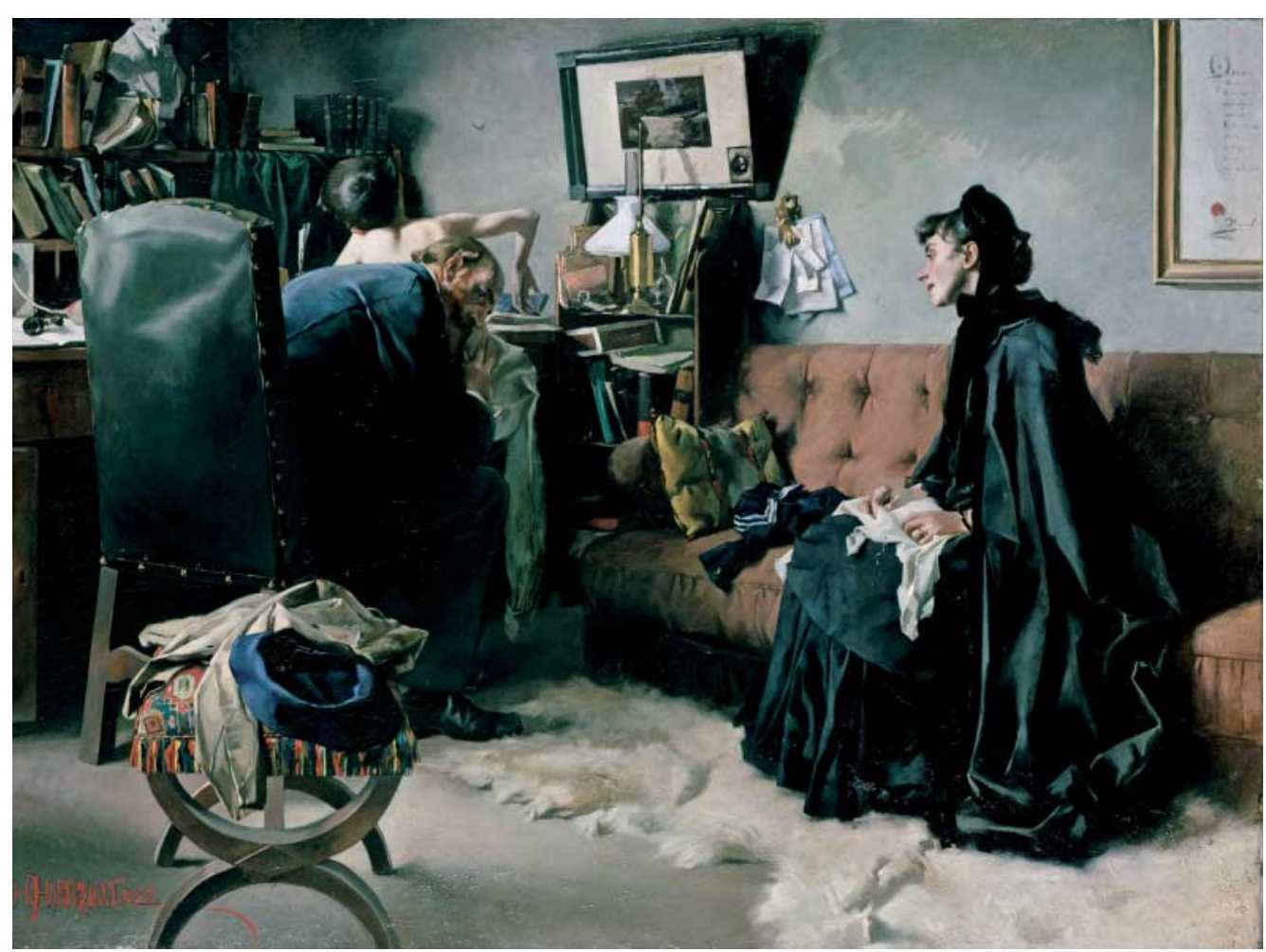

Fig. 1 A delicate child, with permission, Foto Scala, Firenze/BPK, Bildagentur fuer Kunst, Kultur und Geschichte, Berlin

G. Bordin, Ospedale Piccole Figlie, Parma, Italy

e-mail: giorgio.bordin@ fastwebnet.it 